\title{
Effectiveness of Magnesium Sulphate Crystal Fomentation versus Glycerine Magnesium Sulphate Paste Application for Phlebitis among Children Receiving Peripheral Infusion in Krishna Hospital, Karad
}

\author{
Shalumol C George ${ }^{1}$, Dr. Sunita H Tata ${ }^{2}$ \\ ${ }^{1}$ Msc $2{ }^{\text {nd }}$ yr, Karad, Maharashtra, India \\ ${ }^{2}$ Nursing Director, KH, Karad, Maharashtra, India
}

\begin{abstract}
Introduction: Peripheral infusion is commonly used for children. Since children have to undergo many infusions for the administration of medications they will be at a higher risk of developing phlebitis. Objectives: To determine the severity of phlebitis among children receiving intravenous infusion as measured by phlebitis measurement chart,. To determine the effect of magnesium sulphate crystal fomentation on phlebitis, to determine the effect of glycerin magnesium paste application on phlebitis and to compare the effect of both intervention on phlebitis. Methodology: The study based on Quasi experimental designs.30 patient were selected by simple random sampling technique.standard modified phlebitis rating scale and pain rating scale were used to assess the both experimental(Glycerin Magnesium Sulphate paste application) \& control group (Magnesium Sulphate crystal fomentation). Result: Statistical findings shows that the median of paired observation differences of pain and phlebitis of glycerin magnesium sulphate paste application (experimental group) in children of intravenous therapy related phlebitis is decreased from 3 on the day one to 1 on the day three.The difference is significant at $\mathbf{P}<0.01$.The findings revealed that the The glycerin magnesium sulphate paste application is more effective than that of magnesium sulphate fomentation in treatment of intravenous therapy related phlebitis.
\end{abstract}

Keywords: phlebitis, glycerin magnesium sulphate paste application, magnesium sulphate crystal fomentation, Children, Peripheral infusion

\section{Introduction}

Peripheral infusion is a stressful procedure for children. It is estimated that over $80 \%$ of all children entering hospital to receive IV therapy, some of the minor problems were pain, trauma, swelling, joint immobility, but these can lead to life threatening conditions like thrombosis, embolism, variety of infections and so on. This causes severe problems in circulation. Blood clots can form due to IV therapy, and deep vein thrombosis can be very dangerous. Clots become stuck in important blood vessels and cause tissue damage or death $^{1}$.

\section{Review of Literature}

A study was conducted by Brincy Loyolla D'souza \& Shivakumar on 2010 to determine the effectiveness magnesium sulphate crystal fomentation vs. glycerin magnesium sulphate paste application for phlebitis among children receiving peripheral infusion and it found that Glycerin magnesium sulphate paste was effective in reducing swelling and in duration when compared to magnesium sulphate crystal fomentation. ${ }^{2}$

A study was conducted by Junia.D. Susanna, Sr. Winnifred D' Souza(2014), Malarvizhi, to identify the effectiveness of fresh aloevera and glycerin magnesium sulphate application on phlebitis among children.. Thus the study concludes that there was a significant difference in both fresh aloevera and glycerine magnesium sulphate group on the severity of phlebitis. $^{3}$

A quasi experimental study was conducted by Ravindra HN Patel Krupa D (2015) to evaluate effectiveness of glycerin magnesium sulphate dressing on phlebitis among patients undergoing peripheral intravenous infusion. In the research study, findings revealed that Glycerin Magnesium sulphate dressing is highly effective in decrease phlebitis level to the patients. $^{4}$

\section{Materials and Methods}

The study used the quasi-Experimental research design. 30 patient with phlebitis were selected from Krishna Hospital, Karad by simple random sampling technique.standard modified phlebitis rating scale and pain rating scale were used to assess the both experimental(Glycerin Magnesium Sulphate paste application) \& control group (Magnesium Sulphate crystal fomentation)

Inclusion Criteria: Children between 4 to 18 years of age receiving peripheral infusion, Children with phlebitis, Conscious children and receiving peripheral infusion through cannula., Children who do not suffer from any skin disorders in extremities., Children who are willing to participate in the study 


\section{International Journal of Science and Research (IJSR) \\ ISSN (Online): 2319-7064 \\ Index Copernicus Value (2013): 6.14 | Impact Factor (2015): 6.391}

Exclusion Criteria: Children who are severely ill, dehydrated, burns and unconscious., Children who received analgesic, Children with central infusion lines, Children receiving blood and blood products, Children on chemo therapeutic intravenous drugs, Children who are mentally challenged.

\section{Description of the Tool}

The study aimed to evaluate the effectiveness of magnesium sulphate crystal fomentation versus glycerin magnesium sulphate paste application for phlebitis among children receiving peripheral infusion, An observational checklist was developed which include modified Phlebitis Measurement Scale by Jackson Andrew for assessing the severity of phlebitis and Visual analogue pain rating scale for assessing the severity of pain.

\section{The Tool Consists of three Sections}

SECTION I: Demographic data of child and Data related to intravenous infusion

Demographic data comprises of 8 items for obtaining information regarding clinical impression like age, sex how many hours the IV line present before getting the phlebitis, site of intravenous line, type of intravenous solution, type of intravenous therapy, and severity of pain of child with phlebitis.

SECTION II: Observation checklist for pain assessment by using Visual analogue pain rating scale

Visual analogue pain rating sacle

0: No pain, 1-2: Mild pain, 3-4: Moderate pain, 5-6: Severe pain, 7-8: Very severe pain, 9-10: worst possible pain

SECTION III: Observation checklist for phlebitis by using Modified phlebitis measurement scale

Phlebitis measurement scale was developed by Jackson Andrew. It consists of 5 scores which includes following 4 parameters.

- Pain at IV site, Redness, Swelling Palpable venous cord Scoring system in Modified phlebitis measurement scale is as follows :

No symptoms: 0, Mild Phlebitis: 1- 5, Moderate Phlebitis: 610, Severe Phlebitis: $11-15$

\section{Results and Analysis}

\section{SECTION -I}

\section{A. Demographic Variables}

1) Distribution of samples according to age

In the experimental group, among 15, 5(33.33\%) of them were between 4-6 and 14-18 years each, and 3(20\%) of them in the age group of $7-9$ years and only $2(13.3 \%)$ is in the age group of 10-13 years. And In the control group, 7 (46.7\%) of them were between the 4-6 years, 6(40\%) are in the age group of $14-18$ years, only $2(13.3 \%)$ is in the age group of 7 9 years. No children were there in the age group of 10-13 years.

Fisher exact test was applied t. $\mathrm{p}$ value $=1$ which shows there is no significant difference between control and experimental group in age.

\section{B. Data related to Intravenous Infusion:}

1) Distribution of samples according to Time in hours the IV line present before getting phlebitis

Fisher exact test was applied by merging the time in hours the IV line present before getting phlebitis as $<24$ hours and $>24$ hours, ). $\mathrm{P}$ value $=1$ which shows there is no significant difference between control and experimental groups.

For both experimental and control groups IV line was present on right side.

2) Distribution of samples according to site of IV line In the experimental group, among 15,7 (46.7\%) of them received intravenous infusion on Dorsal Venous arch (of hand), 5 (33.3\%) of them received intravenous infusion on median vein and only 3 (20\%) of them received intravenous infusion on cephalic vein and In the control group, among 15, $7(46.7 \%)$ of them received intravenous infusion on Dorsal Venous arch (of hand) and cephalic vein each, and only $1(6.7 \%)$ of them received intravenous infusion on median vein.

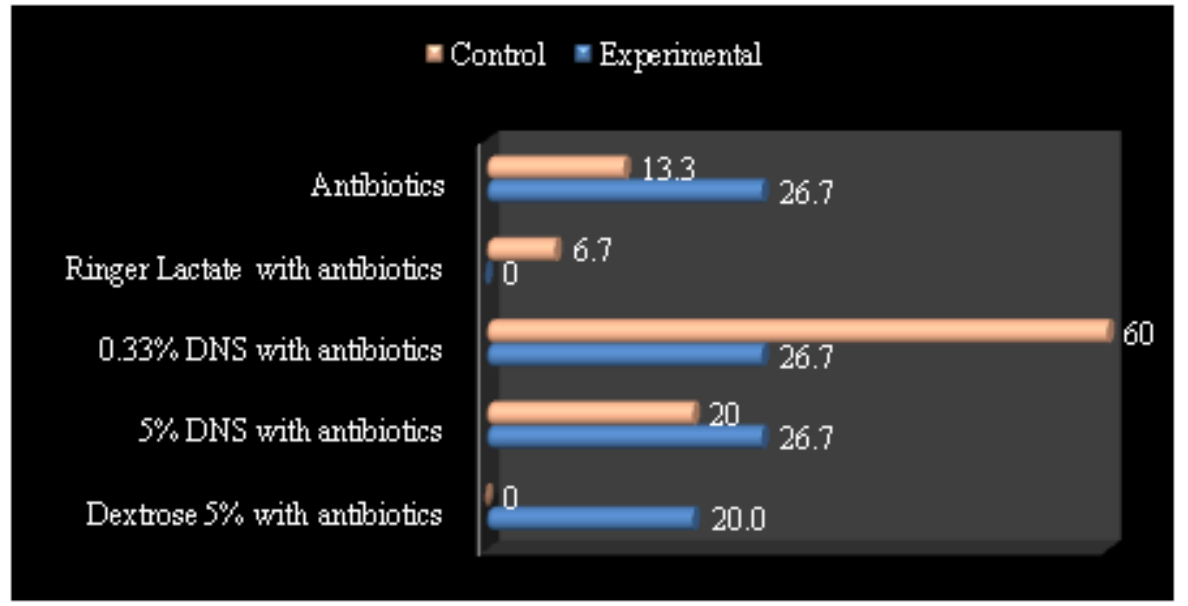

Frequency and Percentage distribution of samples according to type of IV solution, $(\mathrm{N}=30)$

Figure 1: Cylinder bar diagram representing distribution of sample in relation to type of IV solution

In the experimental group, among $15,4(26.7 \%)$ of them received 5\% DNS with antibiotics, $0.33 \%$ DNS with antibiotics and antibiotics each. 3(20\%) received Dextrose $5 \%$ with antibiotics and no one received Ringer Lactate with 


\section{International Journal of Science and Research (IJSR) \\ ISSN (Online): 2319-7064}

Index Copernicus Value (2013): 6.14 | Impact Factor (2015): 6.391

antibiotics. In the control group, among 15, 9 (60\%) of them received $0.33 \%$ DNS with antibiotics, 3(20\%) received 5\% DNS with antibiotics, and 2 (13.3\%) received antibiotics. Only 1(6.7\%) received Ringer Lactate with antibiotics.

4) Distribution of samples according to type of IV therapy

In the experimental group, among 15, 11 (60\%) of them continuous intravenous therapy and 6(40\%) children received intermittent intravenous therapy.

In the control group, among 15, 11 (73.3\%) of them continuous intravenous therapy and 4(26.7\%) children received intermittent intravenous therapy.

5) To determine the severity of phlebitis among children receiving intravenous infusion as measured by phlebitis measurement chart.

In the experimental group, among 15, 4(26.67\%) of them at score 4 i.e. Advanced stage of phlebitis or the start of phlebitis or the start of thrombo phlebitis (Resite Cannulla and can consider treatment ) and 11(73.33\%) of them in the score 3 i.e. Medium stage of phlebitis ( Resite Cannulla and consider treatment.) In the control group, 3(25\%) of them at score 4 and $12(75 \%)$ are at score 3.

\section{Section II:}

1) Table 1: Sum of ranks and median of control group and experimental group on phlebitis after the application of glycerine magnesium sulphate paste and magnesium sulphate crystal fomentation.

\begin{tabular}{|c|c|c|c|c|}
\hline \multirow{2}{*}{ After application } & \multicolumn{2}{|c|}{ Control Group } & \multicolumn{2}{c|}{ Experimental Group } \\
\cline { 2 - 5 } & $\begin{array}{c}\text { Sum of } \\
\text { Ranks }\end{array}$ & Median & $\begin{array}{c}\text { Sum of } \\
\text { Ranks }\end{array}$ & Median \\
\hline Day 1 (1) & 80.5 & 3 & 89.5 & 3 \\
\hline Day 1 (2) & 78 & 3 & 68 & 2 \\
\hline Day 2 (1) & 51 & 3 & 66.5 & 2 \\
\hline Day 2 (2) & 39.5 & 2 & 33 & 1 \\
\hline Day 3 (1) & 40 & 2 & 30 & 1 \\
\hline Day 3 (2) & 26 & 2 & 27 & 1 \\
\hline Friedman Statistic & \multicolumn{2}{|c|}{60.392} & \multicolumn{2}{c|}{72.248} \\
\hline p- value & $<0.001$ & \multicolumn{2}{c}{$<0.001$} \\
\hline
\end{tabular}

(1) represents first reading taken in morning and (2) represents second reading taken at night.

Friedman test was used to perform non parametric repeated ANOVA to check whether there is effect of magnesium sulphate crystal fomentation and glycerin magnesium paste application on phlebitis in control and experimental group respectively. Readings were taken on subsequent three days, two times each day. Above table no 1 depicts readings of phlebitis measurement chart after applying magnesium sulphate crystal and glycerin magnesium paste each time in control and experimental group respectively. It revealed that, there was significant reduction in readings of score of phlebitis measurement chart, after day $1,1^{\text {st }}$ reading, for day 1 (2), day 2(1) (day $1^{\text {st }}, 2^{\text {nd }}$ application, day $2^{\text {nd }}, 1^{\text {st }}$ application and day $3^{\text {rd }}, 2^{\text {nd }}$ application) and so on till day $3(2)$ for both control and experimental groups $(\mathrm{p}<0.001)$.

2) Comparison among magnesium sulphate crystal fomentation versus glycerin magnesium sulphate paste application for phlebitis among children receiving peripheral infusion in terms of reduction in phlebitis.

Table 2: Shows the Median, U statistic and p value of control group and experimental group on phlebitis.

\begin{tabular}{|c|c|c|c|c|c|}
\hline \multicolumn{2}{|c|}{ Readings } & Group & Median & U statistic & p value \\
\hline \multirow{4}{*}{$\begin{array}{c}\text { Day } 1 \\
\text { (1) }\end{array}$} & \multirow{2}{*}{ Before } & Control & 3 & \multirow{2}{*}{240} & \multirow{2}{*}{0.692} \\
\hline & & Experimental & 3 & & \\
\hline & \multirow{2}{*}{ After } & Control & 3 & \multirow{2}{*}{240} & \multirow{2}{*}{0.692} \\
\hline & & Experimental & 3 & & \\
\hline \multirow{4}{*}{$\begin{array}{c}\text { Day } 1 \\
\text { (2) }\end{array}$} & \multirow{2}{*}{ Before } & Control & 3 & \multirow{2}{*}{251} & \multirow{2}{*}{0.353} \\
\hline & & Experimental & 3 & & \\
\hline & \multirow{2}{*}{ After } & Control & 3 & \multirow{2}{*}{314} & \multirow{2}{*}{$<0.001$} \\
\hline & & Experimental & 2 & & \\
\hline \multirow{4}{*}{$\begin{array}{c}\text { Day } 2 \\
\text { (1) }\end{array}$} & \multirow{2}{*}{ Before } & Control & 3 & \multirow{2}{*}{285} & \multirow{2}{*}{0.012} \\
\hline & & Experimental & 2 & & \\
\hline & \multirow{2}{*}{ After } & Control & 3 & \multirow{2}{*}{270} & \multirow{2}{*}{0.066} \\
\hline & & Experimental & 2 & & \\
\hline \multirow{4}{*}{$\begin{array}{c}\text { Day } 2 \\
(2)\end{array}$} & \multirow{2}{*}{ Before } & Control & 2 & \multirow{2}{*}{301} & \multirow{2}{*}{0.001} \\
\hline & & Experimental & 2 & & \\
\hline & \multirow{2}{*}{ After } & Control & 2 & \multirow{2}{*}{323} & \multirow{2}{*}{$<0.001$} \\
\hline & & Experimental & 1 & & \\
\hline \multirow{4}{*}{$\begin{array}{c}\text { Day } 3 \\
\text { (1) }\end{array}$} & \multirow{2}{*}{ Before } & Control & 2 & \multirow{2}{*}{323} & \multirow{2}{*}{$<0.001$} \\
\hline & & Experimental & 1 & & \\
\hline & \multirow{2}{*}{ After } & Control & 2 & 3225 & $<0001$ \\
\hline & & Experimental & 1 & & \\
\hline & Before & Control & 2 & 302 & $<0.001$ \\
\hline Day 3 & Berore & Experimental & 1 & & \\
\hline$(2)$ & After & Control & 2 & 297 & $<0 \Omega 01$ \\
\hline & Arter & Experimental & 1 & 201 & 0.001 \\
\hline
\end{tabular}

(1) represents first reading taken in morning and (2) represents second reading taken at night

The data displayed in table 2 for the median scores before and after day $1,1^{\text {st }}$ reading, for day 1 (2), day 2(1) and so on till day 3(2) in both the experimental and control group. The Mann Whitney $U$ test revealed that there was significant difference between control and experimental groups for score of phlebitis for different interventions $(\mathrm{p}<0.05)$.

For day $1,2^{\text {nd }}$ intervention, after treatment, day 2 and day 3 there is significant improvement for both interventions which means patients readings approaching to normality. The median score in experimental group is steadily reducing (reduction in phlebitis score) which shows glycerine magnesium sulphate paste application is more effective than magnesium sulphate crystal fomentation.

\section{Section III:}

1) Table no:3, Sum of ranks and median of control group and experimental group on pain after application of glycerine magnesium sulphate paste and magnesium sulphate crystal fomentation.

\begin{tabular}{|c|c|c|c|c|}
\hline \multirow{2}{*}{ After application } & \multicolumn{2}{|c|}{ Control Group } & \multicolumn{2}{c|}{ Experimental Group } \\
\cline { 2 - 5 } & $\begin{array}{c}\text { Sum of } \\
\text { Ranks }\end{array}$ & Median & $\begin{array}{c}\text { Sum of } \\
\text { Ranks }\end{array}$ & Median \\
\hline Day 1 (1) & 85.5 & 3 & 88 & 3 \\
\hline Day 1 (2) & 74 & 3 & 68 & 2 \\
\hline Day 2 (1) & 49 & 2 & 61 & 2 \\
\hline Day 2 (2) & 42 & 2 & 47 & 2 \\
\hline Day 3 (1) & 35.5 & 2 & 26 & 1 \\
\hline Day 3 (2) & 29 & 1 & 24.5 & 1 \\
\hline
\end{tabular}




\section{International Journal of Science and Research (IJSR) \\ ISSN (Online): 2319-7064}

Index Copernicus Value (2013): 6.14 | Impact Factor (2015): 6.391

\begin{tabular}{|c|c|c|}
\cline { 2 - 3 } Friedman Statistic & 62.099 & 67.484 \\
\hline $\mathrm{p}$ - value & $<0.001$ & $<0.001$ \\
\hline
\end{tabular}

(1) represents first reading taken in morning and (2) represents second reading taken at night

Friedman test was used to perform non parametric repeated ANOVA to check whether there is effect of magnesium sulphate crystal fomentation and glycerine magnesium sulphate paste application on visual analogue pain rating scale for control and experimental group respectively. It revealed that, there was significant reduction in readings of score of Visual analogue pain rating scale, after application by day $1,1^{\text {st }}$ reading, for day $1,2^{\text {nd }}$ reading, day $2,1^{\text {st }}$ reading and so on till day $3,2^{\text {nd }}$ reading for both control and experimental groups $(\mathrm{p}<0.001)$.In the comparison between the glycerine magnesium sulphate and magnesium sulphate it can be note that there is significant improvement in efficiency of glycerin magnesium sulphate paste application in experimental group than magnesium sulphate crystal fomentation in control group, as reduction in sum of ranks is more in experimental group as compared to control group in pain related to phlebitis among children receiving peripheral infusion.

2) Comparison among magnesium sulphate crystal fomentation versus glycerine magnesium sulphate paste application for pain among children receiving peripheral infusion in terms of reduction in pain score.

Table 4: Shows the Median, U statistic and p value of control group and experimental group on pain.

\begin{tabular}{|c|c|c|c|c|c|}
\hline \multicolumn{2}{|c|}{ Readings } & Group & Median & U statistic & p value \\
\hline \multirow{4}{*}{ Day 1 (1) } & \multirow{2}{*}{ Before } & Control & 3 & \multirow{2}{*}{225} & \multirow{2}{*}{0.715} \\
\hline & & Experimental & 3 & & \\
\hline & \multirow{2}{*}{ After } & Control & 3 & \multirow{2}{*}{225} & \multirow{2}{*}{0.715} \\
\hline & & Experimental & 3 & & \\
\hline \multirow{4}{*}{ Day 1 (2) } & \multirow{2}{*}{ Before } & Control & 3 & \multirow{2}{*}{221.5} & \multirow{2}{*}{0.632} \\
\hline & & Experimental & 3 & & \\
\hline & \multirow{2}{*}{ After } & Control & 3 & \multirow{2}{*}{259} & \multirow{2}{*}{0.246} \\
\hline & & Experimental & 2 & & \\
\hline \multirow{4}{*}{ Day 2 (1) } & \multirow{2}{*}{ Before } & Control & 3 & \multirow{2}{*}{272.5} & \multirow{2}{*}{0.069} \\
\hline & & Experimental & 2 & & \\
\hline & \multirow{2}{*}{ After } & Control & 2 & \multirow{2}{*}{225} & \multirow{2}{*}{0.715} \\
\hline & & Experimental & 2 & & \\
\hline \multirow{4}{*}{ Day 2 (2) } & \multirow{2}{*}{ Before } & Control & 2 & \multirow{2}{*}{245.5} & \multirow{2}{*}{0.501} \\
\hline & & Experimental & 2 & & \\
\hline & \multirow{2}{*}{ After } & Control & 2 & \multirow{2}{*}{256.5} & \multirow{2}{*}{0.266} \\
\hline & & Experimental & 2 & & \\
\hline \multirow{4}{*}{ Day 3 (1) } & \multirow{2}{*}{ Before } & Control & 2 & \multirow{2}{*}{296} & \multirow{2}{*}{0.004} \\
\hline & & Experimental & 1 & & \\
\hline & \multirow{2}{*}{ After } & Control & 2 & 2875 & 0.013 \\
\hline & & Experimental & 1 & $28 \% .5$ & 0.013 \\
\hline & Before & Control & 2 & 2875 & 0013 \\
\hline Dav 3 (2) & Belore & Experimental & 1 & $28 \% .5$ & 0.013 \\
\hline Day $S(z)$ & After & Control & 2 & 293 & 0006 \\
\hline & Atter & Experimental & 1 & 293 & 0.006 \\
\hline
\end{tabular}

(1) represents first reading taken in morning and (2) represents second reading taken at night

The data displayed in table 4, for the median scores for Visual analogue scale, before and after day $1,1^{\text {st }}$ reading, for day 1 (2), day 2(1) and so on till day 3(2) in both the experimental and control group.

The Mann Whitney U test revealed that there was significant difference between control and experimental groups for score of Visual analogue pain rating scale for different interventions $(\mathrm{p}<0.05)$.

1) For day 2(1) before applying magnesium sulphate crystal fomentation and glycerine magnesium sulphate paste application in control and experimental group respectively.

2) Here, although the difference $(p=0.069)$ did not reach the level of significance, the p-value was very close and approaching the level of significance.

3) For day 3(1) before and after applying magnesium sulphate crystal fomentation and glycerine magnesium sulphate paste application in control and experimental group respectively.

4) For day 3(1) before and after applying magnesium sulphate crystal fomentation and glycerine magnesium sulphate paste application in control and experimental group respectively.

After day 2, on day 3 there is significant improvement for both interventions which means patients readings approaching to normality.

\section{Discussion \& Summary}

Total 30 children with phlebitis were selected for the research study, by simple random sampling method.Among 30, 15 children for the control group (magnesium sulphate crystal fomentation ) and 15 for the experimental group (glycerin magnesium sulphate paste application).The phlebitis and phlebitis related pain where assessed by Visual analogue scale, pain rating scale.The study conclude that there was a significant increase in the let down score in experimental group than the control group. Therefore the research hypothesis, $\mathrm{H}_{1}$ is accepted. Thus, application of glycerin magnesium sulphate paste application is more effective than magnesium sulphate crystal fomentation in reducing phlebitis and phlebitis related pain in children receiving peripheral infusion.

As the glycerin magnesium sulphate paste is cost consuming, easy to apply and more effective in reducing phlebitis it can be recommended but the sample size is small, it can't be generalized to all children with phlebitis.

\section{Acknowledgement}

The Author is thankful to administrative authority of Krishna Institute of Nursing Sciences and Krishna Hospital for their cooperation.

\section{References}

[1] Peripheral venous catheter [Internet]. Wikipedia. 2016 [cited 14 December 2015].Available from: https://en.wikipedia.org/wiki/Peripheral_venous_catheter

[2] Brincy Loyolla D'souza \& Shivakuma. Effectiveness Magnesium Sulphate Crystal Fomentation Vs Paste Application for Phlebitis among Children Receiving 


\section{International Journal of Science and Research (IJSR) \\ ISSN (Online): 2319-7064}

Index Copernicus Value (2013): 6.14 | Impact Factor (2015): 6.391

Peripheral Infusion who are Admitted at Selected Hospital at Mangalore NUJHS Vol. 6, No.1, March 2016, ISSN 2249-7110.

[3] Junia.D. Susanna, Sr. Winnifred D' Souza, Malarvizhi, M. Effectiveness of fresh aloevera and glycerine magnesium sulphate application on phlebitis among children. International Journal of current research: 2014July; 6(7):7477-9.

[4] Ravindra HN, Patel Krupa D. A quasi experimental study to evaluate effectiveness of glycerin magnesium sulphate dressing on phlebitis among patients undergoing peripheral intravenous infusion in selected hospital, vadodara: Int J Med Res Health Sci.2015;4(3):527-530.

\section{Author Profile}

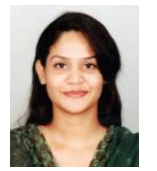

Ms. Shalumol.C.George, $2^{\text {nd }}$ year Msc(n) Student, Krishna Institute of Nursing Sciences, Karad. KIMSDU, India

Dr. Sunita. H. Tata has done B.A.(Hon's)R.N.R.M, Msc Child Health Nursing) PhD. She is Associate Professor \&Nursing Director, Krishna Hospital, Karad, Maharashtra, India 